\title{
The Participation of the Saudi Youth in the Services of Pilgrims, Which Leads to the Provision of A Job Opportunity Through the Work of Various Spy Committees Under the Supervision of the Saudi Security
}

\author{
Dr. Ghada Mohammed Orifi \\ King Abdulaziz University, Jeddah Al-Basateen District, Beside Saad El Din Sweets Prince Sultan Street
}

\begin{abstract}
No country in the world can spend more than 100 billion riyals to build infrastructure, create a city full of services, government facilities, hospitals, a network of connections, roads and tunnels to operate for only one week each year and then shut down only the Kingdom; In order to serve pilgrims and guests of the House of Allah.The service of Hajj is not a political or media manifestation taken by the government in order to win the satisfaction of international organizations, but it is a doctrine that believes in and implements it on the ground, without any intention. The offer has been generously honored since the establishment of this state by its founder King Abdulaziz - may God rest his soul.It may not be known that the fees for the services of the heads of the communities from the tents in Mina, their transportation and their services, 40 years ago fixed prices did not rise, despite the demand of these institutions to increase prices, but the State decided not to load pilgrims coming from abroad any increase in prices, Hajj no more than 1029 riyals, the wages of tents in Mina and Arafat and the movements in Mecca and Madinah, despite the past years of instability in oil prices and the decline in the income of the Kingdom, which depends heavily on its revenues. The Government of Saudi Arabia pays great attention to pilgrims abroad, and gives them all facilities and preference in service, even pilgrims of citizens and residents do not receive these services and facilities $85 \%$ of the camps of Mona and Arafat, all for pilgrims abroad, and the rest are for pilgrims inside, Of the advantage of receiving them in a specialized city for pilgrims at Jeddah airport, and does not enjoy the low fees paid by pilgrims abroad, the cost of pilgrimage for Saudis and expatriates exceeds the prices of pilgrims abroad hundreds of times, so as not to cause pilgrims inside the harassment of those coming from abroad, And sanctioned those who violate these regulations, including: the non-Hajj only with the permission of government agencies, and included sanctions expulsion from the country to the residents of violators and imprisonment and the financial fine of citizens.A fully functioning civilized city can only be established for a week. They are equipped with 200 thousand security men, with all their security equipment and the highest training. They do not get any fees from the pilgrims, or impose taxes or refunds to them when they leave. What is striking is that the Saudi government has paid a month's reward to the Hajj employees of the security forces, all in order for pilgrims to enjoy safety and security while they are in Makkah, Madinah and in pilgrimage sites.
\end{abstract}

Keywords: Saudi youth, services of pilgrims, Saudi security

DOI: $10.7176 / \mathrm{EJBM} / 11-9-12$

Publication date:March $31^{\text {st }} 2019$

\section{Introduction}

The Kingdom has not used the pilgrimage season to promote a political position or to obtain the support of international organizations for a position that has worked and is still silently being paid by the Almighty. It is known that a gathering of people in a limited area of Sharia to carry out activities required in specific hours and languages Different cultures and religious doctrines, among them the owners of tribal and tribal dynasties, in addition to what happens in the Arab and Islamic world of doctrinal differences and the political events in the region, and to control all these masses and take into account all the political circumstances requires the skill and skill and art of management.

There is no doubt that the building of the Sacred Mosque, and the service of pilgrims and Umrah, is one of the most important virtues of Saudi Arabia, especially during the pilgrimage season, every year.

\section{Research topic \\ Definition of participation}

Participation in public life means the contribution of individuals to the management of their society, the expression of opinion, and the taking of initiatives aimed at achieving local and national benefit. The right to participate is part of political freedoms, but the concept of participation goes beyond being just a right. It is a culture that is in contrast to the culture of non-majority, despair and reluctance, which means the need for each society to consolidate it through democratic upbringing based on continuous mobilization and training. Democracy lies in the will of citizens to act responsibly in public life, to participate with others in public administration, to choose their representatives, and to evaluate their performance. Together, these processes have limited the democratists 
to talk about the democratic mentality associated with training and good practice.

As well as ... Youth face a great challenge when dealing with the issue of participation in public life, this challenge is to lose the true concept of participation amidst thousands of concepts that develop and interfere daily in our lives and find ourselves panting behind them to realize their meanings.

The importance of participation for youth:

The concept of participation refers to the process of integrating young people into decision-making that affects their lives, including their contribution to identifying their personal needs and the needs of their community, and proposing solutions and interventions to develop and modernize their societies.

The following set of values can be deduced from the concept:

-Participation is cooperation with the rest of the community in the future industry and solve problems, and develop its capabilities.

-Participation works to exchange ideas, opinions, experiences and cultures with others.

-Participation is an opportunity for innovation, innovation and keeping abreast of the developments of the times. -Participation requires self-denial, the spirit of team spirit and the interest of the community in the spirit of the individual and personal interest.

To participate in public life, there are several benefits for young people and society:

\section{First: the return on youth}

1-.Young people acquire planning, leadership, teamwork and many other life skills.

2- develop a sense of responsibility towards society.

3- develop a sense of self-esteem, and confidence in self-abilities.

4- Young people gain respect for the rest of society.

5- They develop a sense of the individual's worth and need for society.

6- Young people gain the power to influence others and the ability to change themselves.

7- Young people learn the foundations and foundations of the exercise of democracy at the individual and community level.

8- Young people are able to acquire life skills and experiences that will benefit them in future work.

Second: the return on society, the participation of young people working on

1- the possession of young creative energies enable him to put forward new and innovative solutions to many of the problems of society, such as the problems of unemployment, illiteracy and poverty.

2- Youth is an important human resource for development processes within society. Through scout organizations, NGOs, schools and other community institutions, they can contribute to environmental conservation, rationalize the consumption of non-renewable resources, adult education, help the needy and care for the sick and the elderly. ...etc.

3- Youth participation in decision-making processes ensures that the community has future leaders capable of taking full responsibility for maintaining the security and safety of society and upgrading its capabilities.

4- The society needs the participation of young people in all its activities in order to make its life vital and to absorb youth within its system.

5- Youth are the leaders of the community in the future, they must prepare them to take responsibility for the future with all its challenges, and this preparation required does not bear fruit only by providing a full opportunity for young people to participate effectively.

\section{Sharing styles:}

In this light, youth participation takes three types:

-The pattern of participation at the individual level is the right of young people to know the decisions that will affect their present or their future at the individual level, such as decisions taken at the family level.

-The type of participation at the level of community organizations, whether governmental, private or private, and the role of youth in decision-making while shaping policies and programs that may have a direct impact on their lives. Youth centers, sports clubs and trade unions.

-The type of participation at the level of the country to which it belongs, namely, the right of young people to participate in the economic, social and political life that constitute the characteristics and characteristics of the state. Examples include youth affiliation to partisan organizations, participation in electoral processes, participation in civic education programs...

\section{How to participate?}

After this knowledge review of the concept and importance of participation, it is necessary to identify the institutions and organizations that allow you to participate within the community. But before you look for a place to exercise your right to participate, you need to remember:

-There is no society without organizations and institutions that offer opportunities for participation.

-There are people waiting for your participation, you just have to go and show your willingness to work with him. 
-Participation is a natural right for you, do not overdo it and stick to it.

-Participation includes duties and rights, you must recognize, accept and abide by.

-Participation highlights your spirit of initiative, so do not wait for someone to invite you to participate, but look for a place where you can exercise this right.

\section{Organizations that allow you to participate:}

In every society there are a number of institutions that allow participation, either by providing opportunities to engage in the implementation of its activities and programs or in the area of membership or in the decision-making within ... All you have to find the institution that feels most appropriate to your abilities and aspirations Among these institutions:

NGOs:

NGOs operate in all societies and take many forms, including charitable and developmental. NGOs are a community entity established by a group of volunteers who love their community. NGOs work in areas such as adult education, orphan child care, environmental conservation, providing loans to the poor, developing youth skills, etc. The NGOs often offer wonderful opportunities for young people to work on one of their developmental or charitable programs. There are advertisements for volunteers to serve their purposes.

Youth Centers \& Clubs:

Are mostly institutions of the state, which provide the opportunity for young people to participate in their sports, social and cultural activities in order to acquire various life skills and prepare them for the future through its various programs.

Scout Associations:

They are spread throughout the Arab countries and have many levels, such as cubs, scouts, mules, etc. The Scouts associations teach young people the skills of self-reliance, initiative, leadership, and positive participation. It is also the best civil institution based on organization and quality management so it offers opportunities for promotion and exchange of experiences among many age groups.

political parties:

They are the institutions that put power and governance as their ultimate goal, through adopting different political approaches. The parties often seek to attract the largest possible number of supporters of their programs and objectives, so they are rich places in the thought of participation should be approached and seize the opportunity in the exercise of true democracy through them.

Volunteer Centers:

Are civil institutions established by some individuals in order to connect volunteer applicants with organizations in need of volunteers. In some cases, these centers carry out development activities and programs through volunteers who recruit them.

Educational institutions:

Such as schools, institutes, colleges and vocational centers, all of which offer opportunities for effective participation through student unions, university families, and through their cultural, social, environmental and other activities.

\section{How to participate:}

\section{-To participate. You have to take the initiative ... I go to participate on your own.}

- First you need to specify the goal you are seeking by searching for a place where you have the right to participate.

-Write this goal in your note, so as not to lose it and you are looking for an institution through which you can achieve your goal.

- Find a previous institution or other organization to achieve your goal.

-Know about the activities and programs of this institution. You can request a leaflet or brochure for this institution to read it well before you decide to participate in its activities.

-If you are convinced of the objectives of this institution and its objectives match with your goal, ask to participate in its programs and activities.

-Usually there is a person responsible for these institutions to accept applications to join the institution, you should identify and introduce yourself to him in a way that encourages him to talk and communicate with you.

-Request to join this institution, and if there is a request to join you fill it and do not hesitate to do so.

-Ask about activities and programs that you can participate in.

Do not forget your goal ... Continue to participate in the institution and do not give up if you meet some challenges.

Remember that there are tests you have to do for yourself, and may include how much you can continue with the activities and programs of the institution that allowed you to participate.

\section{Share Saudi security}

The Kingdom of Saudi Arabia, under the leadership of the Custodian of the Two Holy Mosques, King Salman bin 
Abdulaziz, is making every effort to overcome the difficulties facing the pilgrims, which is inseparable from the vision of the Kingdom of 2030, To develop the system, and to allow more Muslims to perform rituals, at a time of growing Muslims, the importance of preserving their Islamic identity and complete the requirements of their religious rites.

Throughout the course of its history, Saudi Arabia has presented a unique and unprecedented model in the service of the Pilgrimage of the Pilgrims of the House of Allah, a service stemming from its faith and deep belief in the need to provide the best and most important services and means of facilitating this great duty. The Kingdom appreciates the continuous efforts of the Kingdom to facilitate the task of Hajj and what is always stated by the heads of pilgrimage missions who see with their eyes the great projects and services provided by the Kingdom to lead the pilgrims with ease, security and reverence.

This great effort, if we try to count every aspect of it, is a matter of time and time for tens of articles and reports to be confined to it. This is not an exaggeration or a boasting. It is to realize the truth and cut the way for anyone who tries to detract from this blessed effort, For the service of the guests of the Lord, and their sincere efforts.

The role of the security men in Hajj was not limited to their security and traffic role, but went further than that. The finest examples of the purity of dealing with all the pilgrims in the holy places of the holy sites of Mecca and the holy sites were revealed.

The prestige of the security guard .. The humanity without borders The title of the most prominent reality of the Saudi security man in the pilgrimage season, as their spread in the fields of the holy feelings and their concern for the safety and safety of pilgrims and spare them what disturbs the performance of their fate, did not miss the human side Security personnel in the field provide humanitarian services innate for the pilgrims Especially the elderly and children, with an exemplary treatment to paint the joy and pleasure of the lives of the guests of the Lord.

The sectors of the State concerned with the care, care and participation of pilgrims are:

-Ministry of Interior: It carries the bulk of the burdens of care and service of the pilgrims since their arrival in Saudi Arabia, and during their presence in their territory, and even leave the country after performing Hajj rituals. The Ministry of the Interior is at the head of the authorities responsible for receiving the guests of the Lord, conducting transactions to enter the Kingdom's air, sea and land ports, supervising their movement towards the Holy Land, protecting their safety and security, organizing traffic and preserving the safety of pilgrims and their property.

-The Ministry of Defense and Aviation and the National Guard have also made many cooperative efforts with the Ministry of the Interior to maintain order, organize traffic, guide the Red Crescent, Scouts and other relevant bodies.

-The Ministry of Health is one of the most prominent official bodies that have a continuous activity during the Hajj season, both in terms of comprehensive supervision of the health of pilgrims, or in terms of providing various types of health care for them, or in terms of control and control infectious diseases and immediately control, On public health in this Islamic Forum, from the moment pilgrims enter the Kingdom and even leave.

-In addition to these efforts there are ministries and other departments that provide basic services, and monitor the holy sites during Hajj, such as water saving, electricity, telephone communications, and control of what is offered for sale in terms of quality, validity and price control.

All of the above are considered efforts to support the efforts of the Hajj Affairs Authority in the Ministry of Hajj, Endowments, Da'wah and Guidance, which was later separated into two ministries: the Ministry of Islamic Affairs, Endowments, Da'wah and Guidance and the Ministry of Hajj, which specialized in serving pilgrims.

In addition to facilitating the mission of the preachers to Allah on this Islamic occasion, Hajj will not overlook the efforts we are giving him and the care he enjoys from the Arab Kingdom. Saudi Arabia and its Muslim people, to be this care and care and these efforts is the key through which this country and its people enter the hearts of Muslims, and get their proper place is the status of the heart of the body

\section{A simplified proposal for the participation of young people and girls in the service of Hajj}

Through the Hajj season, it is possible to provide employment opportunities for the Saudi youth, and it is an act of worship, besides being a secular one, by serving the pilgrim through the following:

-The establishment of a dedicated administration for these young people and girls through the provision of training courses, including the work of Scouts in addition to the work of Hajj so that the common interest in terms of their access to jobs, and useful to serve the pilgrim

-Youth and girls are divided into groups in different places as needed

Each one of them is delivered a tablet with a database of all the pilgrims. What can be found is a national number for each pilgrim starting from 1 to 7 million. For example, this number helps the team obtain all the Hajj data. In addition, the cards are made of two sides, showing how to perform the rituals and the other is a mini-map so 
that the rituals can be performed as easily as possible. An existing hotline will be worked with this map so that the pilgrim can inquire about what he wants. At the top of the map is a place dedicated to the name of the inquiring pilgrim as well as the national number mentioned above.

These works start from the reception of the pilgrim at the airports and the distribution of these cards to them.

The youth and girls are divided into airports according to the number of groups coming to the Kingdom, which requires coordination and cooperation with the administrations of the Kingdom's airports and the delivery of the paper for each pilgrim, which enables him to reach all the services he will need during the Hajj.

Taking into consideration the cooperation of Saudi security personnel in this new service.

By providing security personnel with each team as soon as possible.

\section{References}

1- Nimr al-Harbi from the book of the invitation during the reign of King Khalid bin Abdulaziz University of Al Madinah Al - Munawwarah

2 - Participation and importance https://mawdoo3.com Concept

3- Abu Ajram, Noha Al-Ghusaini (2006), The Role of Municipal Awareness in Local Development, at the Municipal Work Conference, Bahrain Convention Center, Crowne Plaza Hotel.

4- Ahmad, Ahmed Kamal, Society Organization, Al-Melegi Press, Cairo, 1969

5- Ahmed, Hassan Abdel Basset, Social Development, II, Wajih Library, Cairo, 1985

6- Ahmed, Mohamed Shams El-Din, Supervision of Working with Groups, International Press, Cairo, 1981

7- As'ad, Abdel-Karim, Said, MA, "The Role of Local Authorities in Promoting Participation and Development", An-Najah National University,

8- Badran, Muhammad, The Origins of Administrative Law, Cairo, Dar al-Nahda al-Arabiya, 1990

9- Road, Mohammed Kamel, The Platform for Community Service, Its Origination, Development, Methods, Steps and Organizations, Cairo Modern Library, Cairo, 1968

10- The researcher's vision (Saudi security contribution and some other guarantees in serving the need(

11- The researcher's vision (about developing a simplified plan for a working paper) 